\title{
A Systematic Selection Method Between Neutral and Control of Running Footwear Insole Products
}

\author{
Yang Chenxiao and Li Li Lilly* \\ The Hong Kong Polytechnic University, Institute of Textile and Clothing, Hong Kong
}

*Corresponding author: Li Li Lilly, The Hong Kong Polytechnic

University, Institute of Textile and Clothing, Hong Kong.

Received Date: July 10, 2018

Published Date: July 27, 2018

\begin{abstract}
Running mania has become increasingly prevalent in recent years and its masses is becoming bigger and bigger as well. While, the great majority among them are temporary enthusiastic amateurs, who had little professional training before. They lack specialized knowledge to prevent themselves from injury or fatigue and underestimate the importance of protective running equipment, especially professional running insoles. For example, a certain part of these amateur runners do not know what elements should be considered for better protection and what features should be treated prevailed over the others, when they are choosing professional running insoles.
\end{abstract}

However, there are few researches giving a clear explain on this topic and especially there are entirely different opinions towards professional running insole designs. Therefore, to fill the blank and provide reliable consumer feedbacks for further improvements on professional running insole design, this research aims to examine the performance of insoles by evaluating different terms comprehensively, for example, different materials, shock absorption, loaded pressure, comfort etc. A customized evaluating methodology was established to obtain an all-rounded result.

The research result is reflected from both subjective and objective evaluations, and there is a bias between the objective and subjective results. Therefore, a market gap is revealed accordingly and fair suggestion for selecting professional running insoles and further improvement on its design is provided.

Keywords: Running insoles; Protective; Shock absorption; Comfort level

\section{Introduction}

Nowadays, there is a growing trend of urbanites taking physical training to pursue a healthier life and better body shape. As shown in Figure 1a, the number of joggers in the United States (USA) from the of Spring 2008 to the Spring of 2014 (in million) kept increasing.

Particularly, it raised to 65.48 million by Spring 2014. The running \& jogging shoes market in U.S. was benefited and the sales kept growing as well, especially that in 2012, the sales reached 3 billion U.S. dollars [1], as shown in Figure 1b.

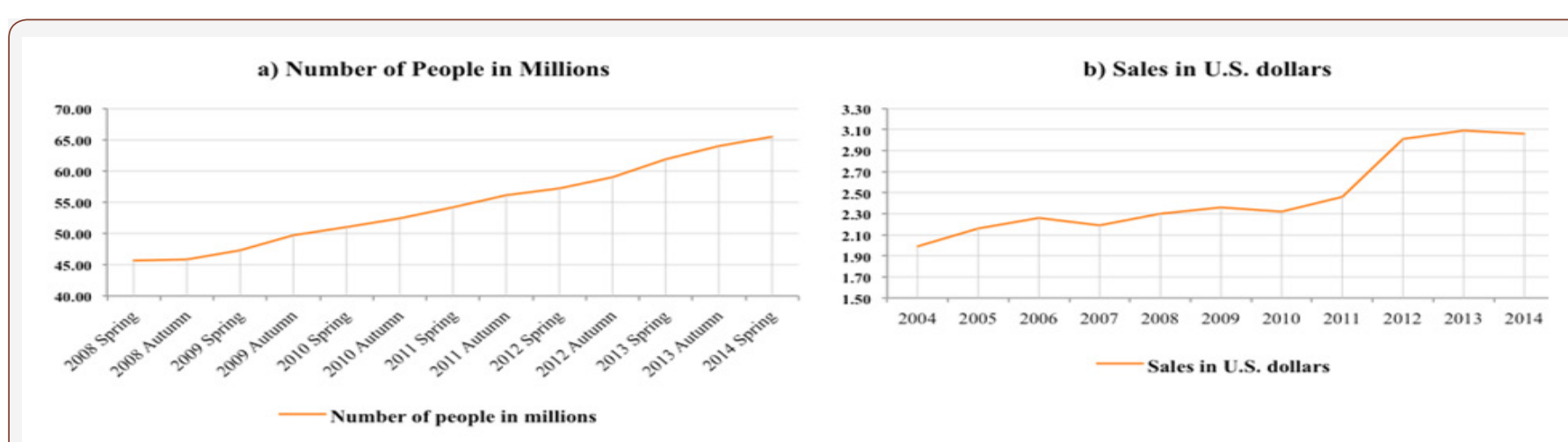

Figure 1: a) Number of runners within the last 12 months in the United States (USA) from the Spring 2008 to the Spring 2014 (in millions) b) Running shoe sales in the U.S. from 2004 to 2014 (in billion U.S. dollars). 
However, does every amateur runner understand the importance of professional running equipment to prevent sports fatigues and injuries, such as patellofemoral pain syndrome (PFPS) and plantar fasciitis spin splints? The answer might be not [2]. They lack specialized knowledge to prevent themselves from injury or fatigue and how to select appropriate protective running equipment, especially professional running insoles. For example, a certain part of these amateur runners does not know what elements should be considered for better protection and what features should be treated prevailed over the others, when they are choosing professional running shoes. Like the compressive stress and shear force generated and reflected to foot specifically, this force could be as heavy as 1.5 to 5 times of body weight. This load can cause micro-trauma to the underlying tissues and may eventually cause permanent damage to the legs. Besides the bottom part of the body, the shock will also transmit to upper part, resulting in maladies of the ankle, knee, hip, and even the lower back [3-6]. Some sorts of injuries can be permanent, especially at the fragile knee joints part. These sports fatigues and injuries will bring lots of inconveniences to the injured daily life and work. Yet, the sock liner (the thin insole that comes with the shoe) found in normal sneakers is designed based on the consideration of outfit rather than safety or the function of cushioning and stabilizing. This gives a persuasive reason why runners should consider professional running shoes with suitable insoles design.

On the other side, although designers and manufacturers understand the essential role of insole in protecting amateur runners, there is still a long way to figure out what is the optimal shape and materials for sports insole design, especially currently there are entirely different opinions towards the topic. Moreover, relevant researches or literature reviews on in-shoe plantar pressure distribution and the comfort levels provided by various insole materials are highly limited. Further, information on neither the selection of materials with different strengths nor the effect of shape for running shoes insole design is insufficient.

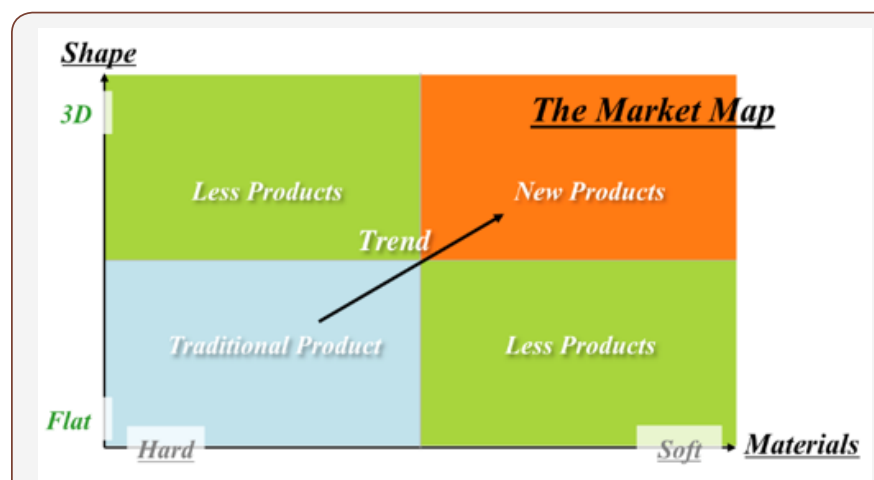

Figure 2: Market segment diagram

Reviewing the current market status, there are two mainstreams: 1) comfort insoles and 2) supportive insoles. The market map is shown in Figure 2. Factors on the x-axis are 1) soft material, 2) hard material; and the ones on y-axis are 3) flat format and 4) multi-dimensional shape. Because when fabricating insoles for comfort, flat and soft materials are selected for intendedly seeking for stronger cushioning and shock absorption effects. Usually, these products are soft and light-weighted. On the other hand, harder materials are selected to provide structural support and stability, especially the midfoot area for supportive insole design. By comparing the working principles of insoles targeting on comfort and support two areas, it can be confirmed that these two segments fall into opposite directions. It causes confusion to consumers when they are facing entirely different designs.

On the market, each running insole has its own supporters. Some investigations found that the application of cushioning insoles can reduce the risk of stress fractures and overuse injuries while some revealed they had no protective function $[7,8]$. On one hand, the supporters of supportive insoles commonly drew their conclusion based on the statistics obtained from various pressure measurements. One indicated that materials could not recover to its original state and failed to give "strength-supportive feeling". On the other hand, supporters for soft insoles came up their conclusion from subjective comfort evaluation. Thus, different attitudes towards these divided markets were caused by different evaluation methodologies [9].

Further, there were several unilateral researches done through objective measurement to quantify the protection effects of running insoles; like C. Leber and P. M. Evanski, conducted the research to assess the performance of 7 pairs of insoles made of different composite materials in terms of plantar pressure relief. A clinical pain could be caused when the average pressure was higher than threshold pressure $398.15 \mathrm{kN} / \mathrm{m} 2$. While the deficiency in the previous researches is that single point of plantar pressure chosen to reflect the comfort degree, which is apparently unconvincing. This objective evaluation methodology ignored the significance of certain factors such as the difference in weights, impact of shoe patterns, differences among pre-designed and customized insoles. Thus, further investigation is necessary to obtain a more comprehensive understanding [10]. On the other hand, limited subjective researches were carried out to evaluate the comfort degree of insoles made of different materials, structure patterns and other factors. Further, rarely there were clear explanation about the relationship between the softness of materials and comfort level. Especially in the subjective evaluating procedure, some paired t-test revealed a huge difference in overall comfort ratings when the test control is compared to the soft insert and to the hard insert $(\mathrm{P}=0.008)$ respectively. The extent of the difference is not the spotlight, but only calculated results are presented $[9,11]$. Therefore, subjective evaluation with further analysis needs to be conducted further.

Additionally, among theseresearches, doesonefactor overweight than the others? Catering to the mass market and different groups of consumers, a balance between different parameters is always the best choice. Comfort degree is one of the main focuses when balancing between the resilience and the supportive strength from the material. Subjective protection effect will be another important factor to evaluate the performance of running insoles. Therefore, this proposed comprehensive methodology combines the views from both objective statistic and subjective methods so that a detailed analysis of the effect on various materials with different strength and shape is given in this research. 


\section{Experimental Design}

\section{Samples of insoles selection}

Referring to customers' various preferences, there are mainly two groups of running insoles: 1) flat or multi-dimensional insoles which are mainly made from compositions of silicon, polymer, foam and textile materials and 2) hard or soft insoles made of similar materials. 8 pairs of insoles, including both flat and multidimensional, with differences in softness were selected as shown in Table 1. The softness would be measured by the degree of deformation under 4 levels of pressures.

Table 1: 8 pairs of insoles sample with different softness selected.

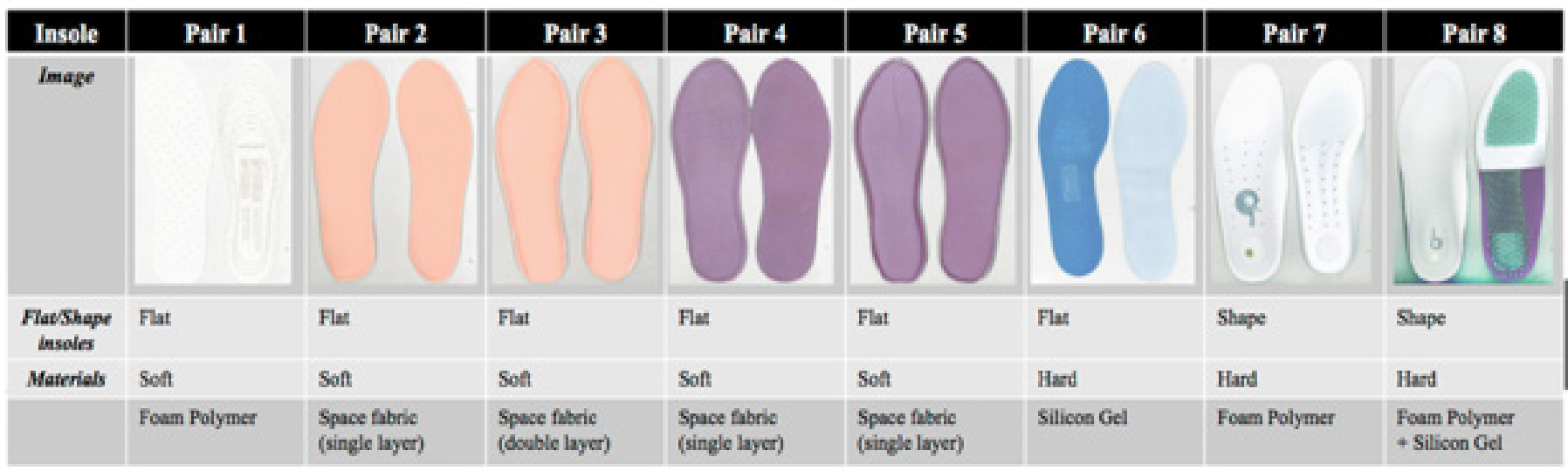

\section{Softness of insoles and deformation evaluation}

4 levels of pressures were selected. The first 6 pairs of flat Figure 3. The deformation in thickness under pressure indicates the materials softness. insoles were tested, and the outcome was shown in Table 2 and

Table 2: Thickness deformation under different pressures

\begin{tabular}{|c|c|c|c|c|c|c|}
\hline $\begin{array}{l}\text { Flat insole / } \\
\text { Pressure }\end{array}$ & Foam Polymer & $\begin{array}{c}\text { Single-layer Space } \\
\text { Fabric } 1\end{array}$ & $\begin{array}{l}\text { Double-layer } \\
\text { Space Fabric } 1\end{array}$ & $\begin{array}{l}\text { Double-layer } \\
\text { Space Fabric } 2\end{array}$ & $\begin{array}{l}\text { Double-layer } \\
\text { Space Fabric } 2\end{array}$ & Silicon gel \\
\hline $4.0 \mathrm{gf} / \mathrm{cm}^{2}$ & Thickness 1-1 & Thickness 2-1 & Thickness 3-1 & Thickness 4-1 & Thickness 5-1 & Thickness 6-1 \\
\hline $34.7 \mathrm{gf} / \mathrm{cm}^{2}$ & Thickness 1-2 & Thickness 2-2 & Thickness 3-2 & Thickness 4-2 & Thickness 5-2 & Thickness 6-2 \\
\hline $70.8 \mathrm{gf} / \mathrm{cm}^{2}$ & Thickness 1-3 & Thickness 2-3 & Thickness 3-3 & Thickness 4-3 & Thickness 5-3 & Thickness 6-3 \\
\hline $101.1 \mathrm{gf} / \mathrm{cm}^{2}$ & Thickness 1-4 & Thickness 2-4 & Thickness 3-4 & Thickness 4-4 & Thickness 5-4 & Thickness 6-4 \\
\hline
\end{tabular}

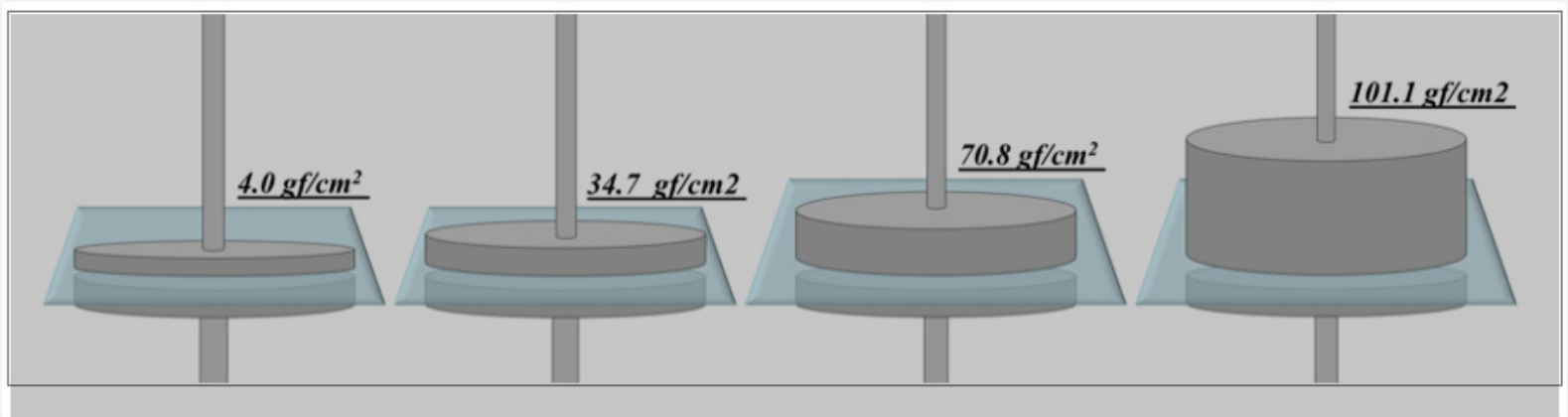

Figure 3: The thickness deformation ( $\Delta$ Thickness) under 4 levels of pressures.

\section{Participants}

7 female volunteers (with foot sizes from 37 to 38, EU standard, aged from 24 to 32, with SD 3.2, height from $153 \mathrm{~cm}$ to $174 \mathrm{~cm}$, with SD 7.09) were selected. All participants did not have any history in foot related disorders, skin lesions or health problems. They were all verbally informed of the trial procedure beforehand so that they were free to control the running speed and step rhythm. Subjects wore their own comfortable running shoes due to different interpretation of comfort which closely relate to personal experiences. Wearing own comfort running shoes eliminated the deviation caused by different attitudes towards a certain running shoe design. Signed written consent was obtained from all participants before the experiment started.

\section{Objective measurement -- pressure sensor testing system}

The Pedar-x is an in-shoe dynamic pressure distribution measuring system which contains capacitive sensors. As shown in Figure 4, the sensors were placed in subject's shoes and insoles (left insole: V-1087l-1082r_2012Jul18, right insole: V-1087l1082r_2012Jul18) to measure the pressure and the shock waves (Fig 3. d). Each subject wore the Pedar-x belt with a box attached 
to their back as shown in the Figure 3a. The box and the sensors were interconnected by some cables. Lastly, Velcro straps were attached around the subject's limbs to secure the cables. At the end the result could be exported into stereo-images.

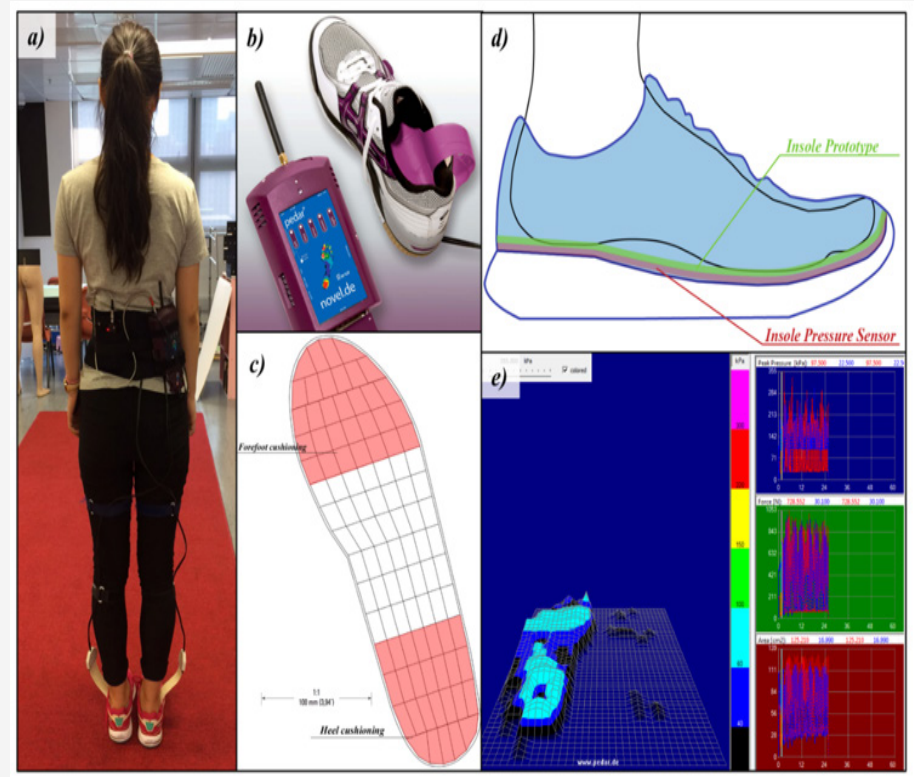

Figure 4: Pedax-x System: a) The prepared subject b) The equipment c) Sensor points allocation d) Prepare the pressure insole sensor and insole samples e) Testing result example

\section{Wear trial procedures}

In this wear trial, 4 gestures including walking, slow run, fast run and stepping, were conducted to measure the maximum pressure and force. The consequences were compared to illustrate the impact of material softness on shock absorption effect. The procedures of each trial started with subject warming up by walking casually around on the red carpet to get used to the new insoles (Speed: around $5.4 \mathrm{~km} / \mathrm{h}$ ). After 3 minutes, 4 gestures would be completed following the sequence that: 1 . Walking (speed: around $5.4 \mathrm{~km} / \mathrm{h}$ ), 2. Slow run (Speed: around $8.7 \mathrm{~km} / \mathrm{h}$ ), 3. Fast Run (speed: around $12 \mathrm{~km} / \mathrm{h}$ ), and 4 . Stepping (beat: $4 / 8,75$ ), as shown in Figure 5 . The stepping gesture is explained in Figure 6.

\section{Running Test Procedures}

\begin{tabular}{|c|c|c|c|c|c|}
\hline Arrival of subjects & & & & & \\
\hline Wear insole Prototype 1 & & & Wear insole $\mathrm{P}$ & & \\
\hline $\begin{array}{c}\text { Walking } \\
(5.4 \mathrm{~km} / \mathrm{h}, 3 \mathrm{~min})\end{array}$ & $\begin{array}{l}\text { Slow Speed Testing } \\
(8.7 \mathrm{~km} / \mathrm{h}, 3 \mathrm{~min})\end{array}$ & $\begin{array}{l}\text { Fast Speed Testing } \\
(12 \mathrm{~km} / \mathrm{h}, 3 \mathrm{~min})\end{array}$ & $\begin{array}{l}\text { Step Testing } \\
(\mathbf{4 / 8 , 7 5} \text {, beats ) }\end{array}$ & $\begin{array}{c}\text { Walking } \\
(5.4 \mathrm{~km} / \mathrm{h}, 3 \mathrm{~min})\end{array}$ & $\cdots \cdot$. \\
\hline
\end{tabular}

Figure 5: Pedax-x System: a) The prepared subject b) The equipment c) Sensor points allocation d) Prepare the pressure insole sensor and insole samples e) Testing result example

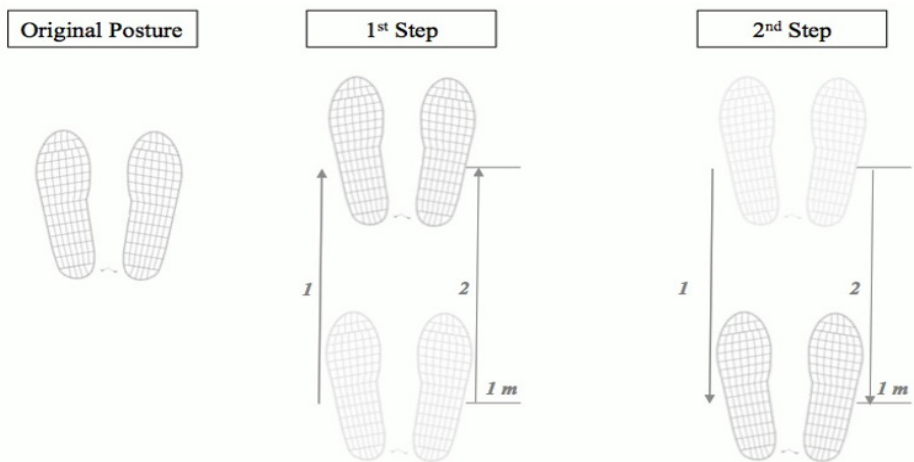

Figure 6: Pedax-x System: a) The prepared subject b) The equipment c) Sensor points allocation d) Prepare the pressure insole sensor and insole samples e) Testing result example 


\section{Subjective evaluation of comfort - questionnaire}

Perceived comfort was evaluated by using a validated Visual analogue scale (VAS, from score 0 to 100,0 presented the worst circumstance and 100 presented the best circumstance). Based on the widely accepted method developed by Mundermann et al. [8] in 2002 (Figure 7), 6 associated factors were selected to be scored by subjects, and they are listed in Figure 8.

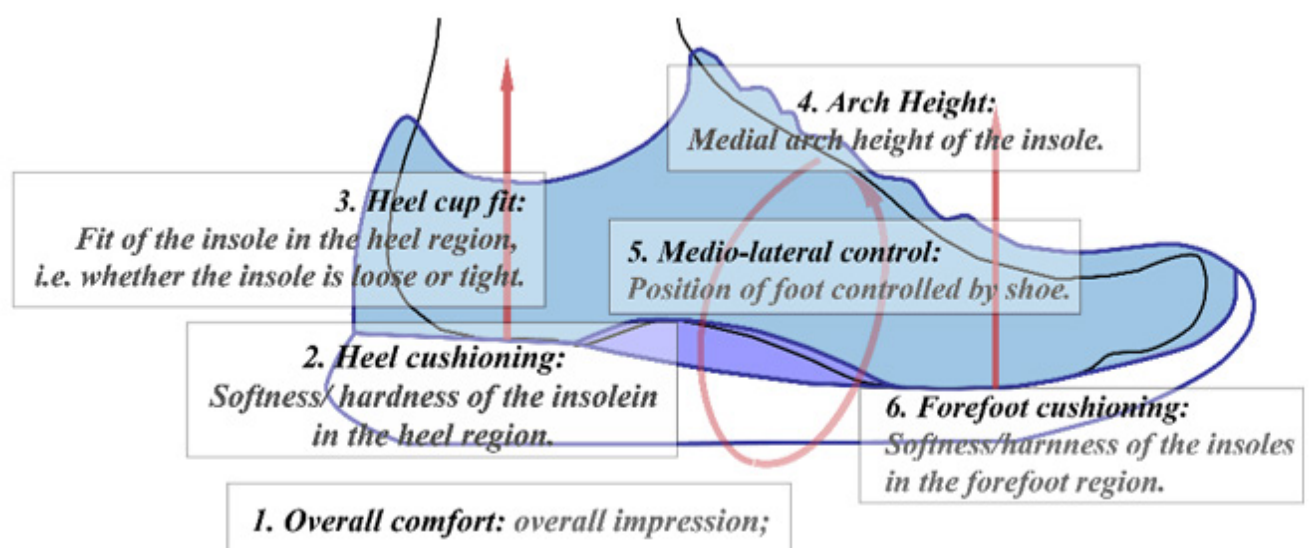

Figure 7: Footwear comfort evaluation factors for running Mundermann et al. [8].

overall comfort
not comfortable

\section{medio-lateral control}

\begin{tabular}{ll} 
not comfortable & \multicolumn{1}{c}{100} \\
at all & most comfortable \\
condition imaginable
\end{tabular}

arch height

$\begin{array}{ll}\text { not comfortable } & \text { most comfortable } \\ \text { at all } & \text { condition imaginable }\end{array}$

heel cup fit

$\begin{array}{ll}\text { not comfortable } & \begin{array}{l}\text { most comfortable } \\ \text { at all }\end{array}\end{array}$

Figure 8: 6 VAS score factors.

\section{Statistical Analysis}

ANOVA methodology was adopted to analyze the co-relationship among insoles' softness, shape, mean maximum pressure, impact Test Results

\section{Material softness test - flat insole thickness deformation}

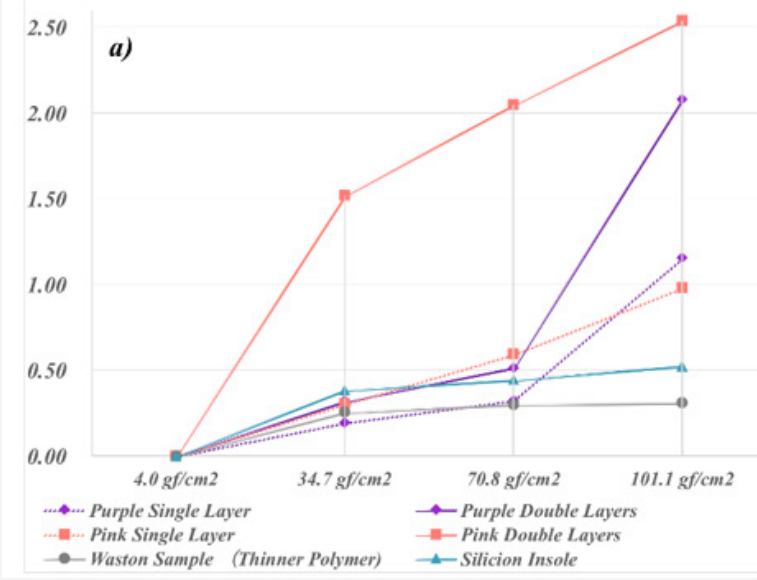

force, comfort level and overall protection so to reveal the principle hidden behind.

Figure 9: Testing result: a) absolute $\Delta$ Thickness deformation under different pressures b) $\%$ of $\Delta$ Thickness deformation under different pressures. 
Absolute deformation in thickness and change in percentage (\%) under different pressures are shown in Figures 9a \& 9b. When the loading increased, the deformations in thickness of Pair 3 \& 5 (double-layer space fabric $1 \& 2$ material) were the most significant due to their double-layer structure. Meanwhile, the declining slope reflects that space fabric 1 and silicone gel changed most rapidly with small pressure loaded while space fabric $1 \& 2$ deformed the most when high pressure loaded.

Further, among the 4 gestures, fast run triggered the biggest pressure and thus most deformation data were received during this stage, which required for better shock-absorptive protection. Conversely, walking induced the least pressure so smaller deformation was generated and fewer requirements on shock absorption would be required. This also indicated that professional running insole was important to provide better shock-absorptive protection for amateur runners.

Maximum Force $[\mathrm{N}]$ and Maximum Pressure [kPa]

\section{Comparison of average max loads of 4 gestures among 8 samples of insoles}
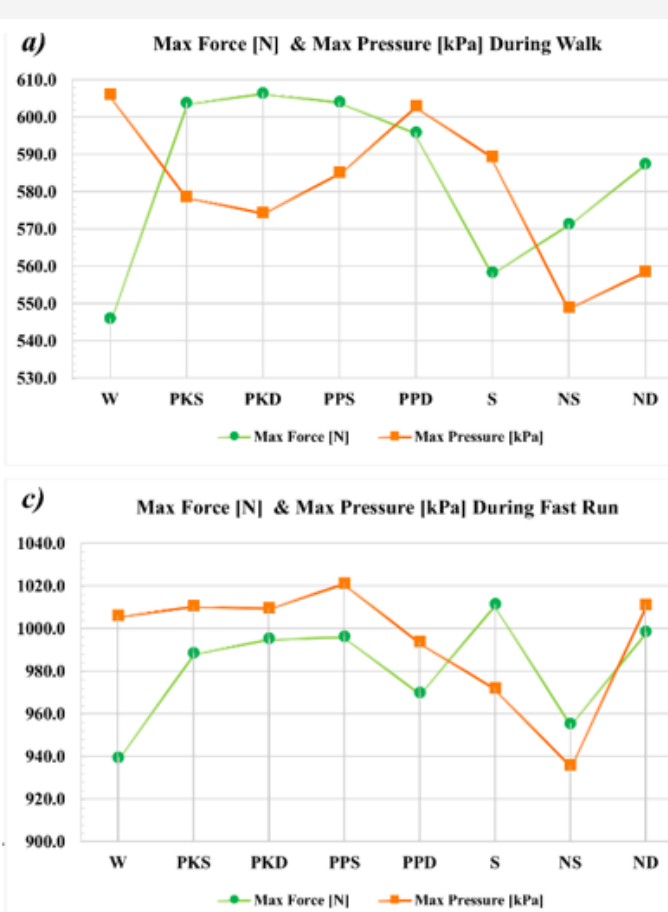

b)
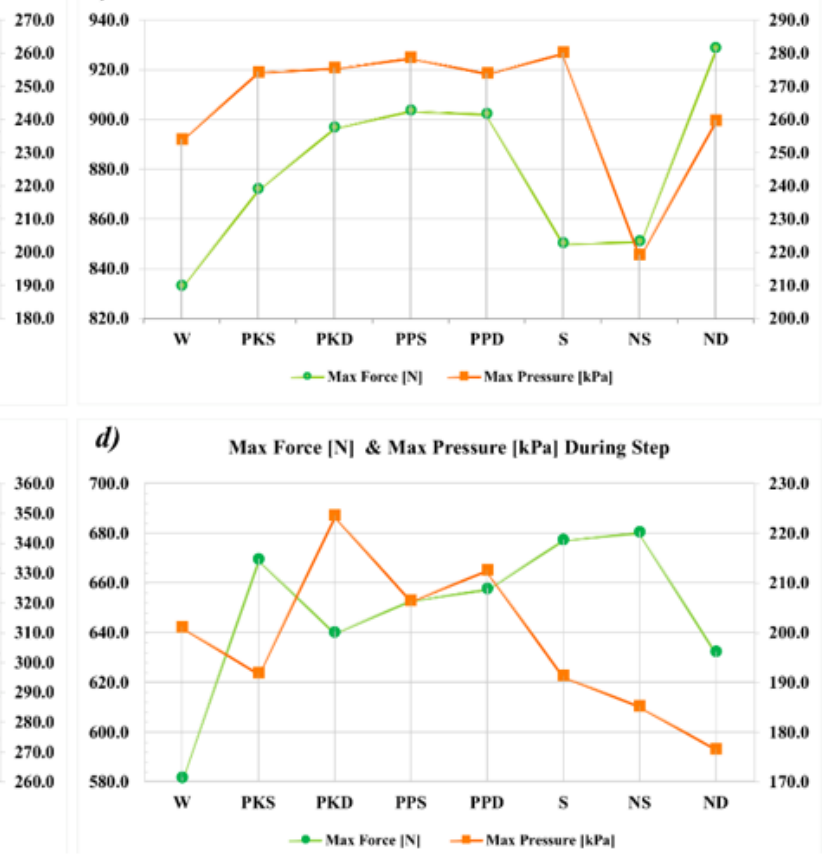

Figure 10: Mean Max Forces $[\mathrm{N}]$ and Max Pressures $[\mathrm{kPa}]$ of 7 subjects during 4 gestures by wearing 8 different insole samples.

The average values of the Maximum Force $[\mathrm{N}]$ and Maximum Pressure $[\mathrm{kPa}]$ of 7 subjects suffered through 4 gestures are calculated and presented in Figures 10a-10d. The comparison was within 8 pairs of insoles with 4 proposed gestures. Comparing the values of loads, the order from the maximum to the minimum are as follows: fast run, slow run, stepping, walking. The pattern of maximum pressure exhibited the same trend. From Figures 10a-10d, it demonstrated an inverse relationship between maximum force and maximum pressure when subjects walked and stepped while Figures $10 \mathrm{~b}, 10 \mathrm{c}$ showed a positive-related relationship between maximum force and maximum pressure when subjects doing slow run and fast run. This relationship revision might be caused by the insole deformation under high pressures generated when doing slow and fast run. Insignificant insole deformation triggered larger contact area between insoles and foot, which contributed to the pressure decrease. While significant insole deformation could not provide sufficient contact area to absorb the shock when high pressure loaded, thus, the tested pressure increased with the force. This finding indicates that when designing for causal sneakers, soft insole materials might be a good choice, but they are not ideal for professional running insole or shoes design. Instead supportive materials would be a better choice.
What is more, referring to Figures 10b,10c the mean Max Force/ Pressure of Insole W/ S/ NS were relatively low while the values of PKS/ PKD/ PPS/PPD were high. The effectiveness and protective effects should be considered together with the following subjective questionnaire feedback for further investigation.

The average values of the Max Force [N] and Max Pressure [kPa] of 7 subjects received during 4 gestures were calculated respectively and shown in Figure 11. Different materials were divided into 4 groups and comparison were made internally of each group as shown in Table 3. The result from Material Group (a) listed in Table 4 reflects that there was no certain pattern discovered when comparing the foam polymer and silicone gel. Also, the difference between flat insole and shape insole is insignificant when comparing Group d) to Group a). Yet, some useful information could still be found.

In contrast, a diverse result can be found when comparing the Group b) to c). Besides, NS (merely foam polymer material) performed better than the others. What is more, the deformation in thickness for layers was different that it has an impact on comfort level. It draws to the conclusion that the shock absorption effects were heavily depended on the kind of space fabric materials 
instead of numbers of layers. For this reason, the following section would synthesize the comments from subjective questionnaires with the statistics to evaluate the overall protective effects.
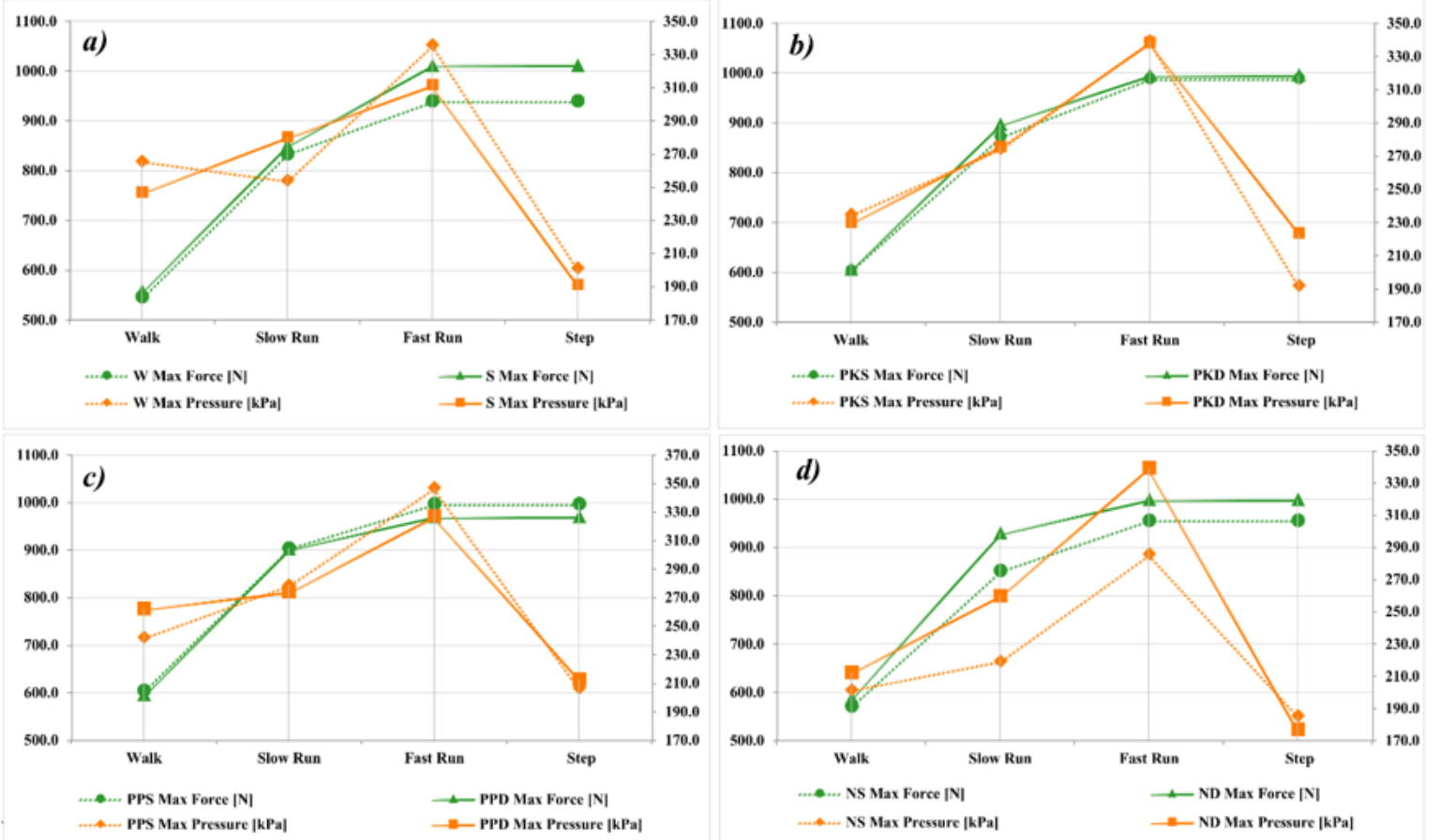

Figure 11: compare mean Max Forces [N] and Max Pressures [kPa] of 7 subjects tried 8 samples in 4 groups.

Table 3: Internal relationship analysis between force/pressure and activities.

\begin{tabular}{|c|c|c|}
\hline & Low Force/ Low Pressure Group & High Force/High Pressure Group \\
\hline Activity & Walking <Stepping & Slowly Running < Fast Running \\
\hline Relationship between Force \& Pressure & Inverse relationship & positive relationship \\
\hline
\end{tabular}

Table 4: Comparison in different material groups.

\begin{tabular}{|c|c|c|c|c|}
\hline \multirow{2}{*}{ Materials } & Group (a): & Group (b): & Group (c): & Shape Insoles \\
\cline { 2 - 5 } & Traditional Material & Space Fabric 1 & Space Fabric 2 & Foam Polymer combined Silicon \\
\hline \multirow{2}{*}{ Insole Prototype } & Foam Polymer (W) & Single Layer (PKS) & Single Layer (PKS) & Foam Polymer (NS) \\
& Vs Silicone Gel (S) & Vs Double Layer (PKD) & Vs Double Layer (PKD) & Vs Foam Polymer + Silicone Gel (ND) \\
\hline \multirow{2}{*}{ Result } & Force: $\mathrm{S}>\mathrm{W}$ & Force: PKD $\approx$ PKS & Force: PPS $>$ PPD & Force: ND > NS \\
& Pressure: Random & Pressure: PKD $\approx$ PKS & Pressure: PPS $>$ PPD & Pressure: ND $>$ NS \\
\hline
\end{tabular}

\section{Subjective test result}

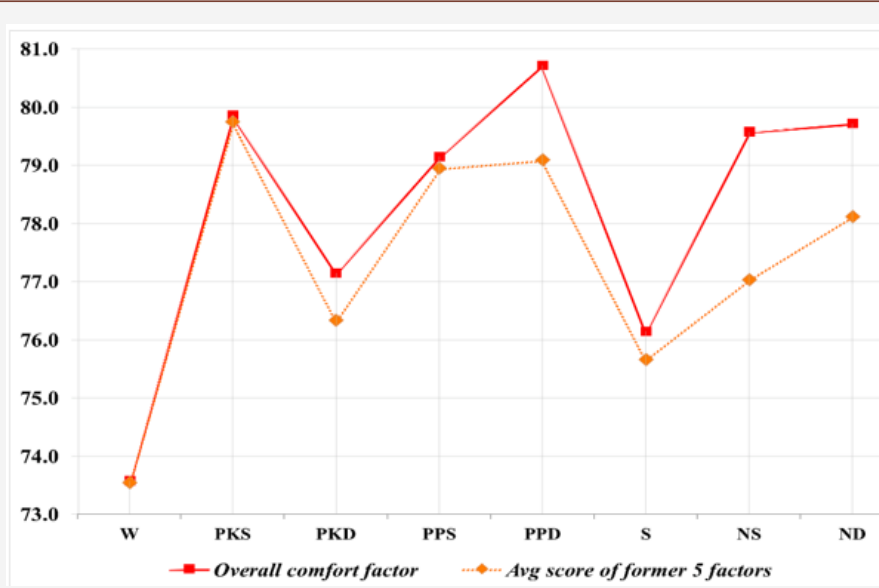

Figure 12: The overall comfort score \& average score of former 5 factors of 8 insole samples. 
Average score analysis: The outcome of subjective questionnaire was organized and presented in Figure 12. From the chart, there is a strong relevance among the overall comfort scores with the average scores of the former 5 factors. Both the contradiction and interrelated results reflected in the subjective comments and objective shock absorption measurement result were listed in Table 5.

Table 5: Comparison link established between force/pressure absorption effects and subjective score.

\begin{tabular}{|c|c|c|}
\hline & Force/Pressure Absorption Effects & Subjective Score \\
\hline Low & PKS/ PPS/ PPD/ PKD & W/S/PKD \\
\hline High & W/S/ NS & PKS/ PPS/ PPD \\
\hline
\end{tabular}

First, the insoles made with PKS/ PPS / PPD obtained high scores, but the shock absorption effect was not ideal. The contradictive result was unexpected as space fabric deformed the most and the shock absorption effect was poor but gained high scores in subjective evaluation. It indicated that the softness of materials would misguide consumers when assessing the comfort and actual protective effect. In addition, PKD, made of space fabric 1 , even performed poorly in both objective and subjective evaluation. Per the feedbacks from several subjects, it was too bulky although the soft material enabled to adapt to the force increasing quickly. Again, this proves the balance between softness and material volume (thickness) is extremely important. It might be the bulky volume influenced the sensing score on the 6 VAS score points (Figure 13).

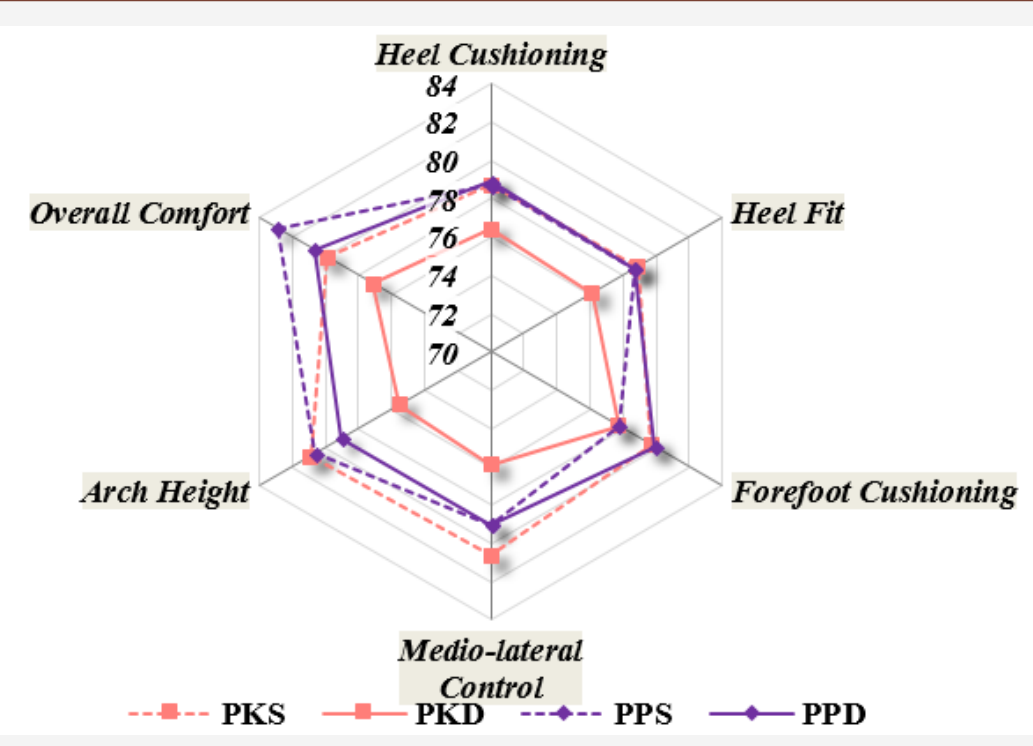

Figure 13: The analysis of subjective evaluation of insole samples PKS/ PKD/ PPS/ PPD made by 2 kinds of space materials.

Moreover, the subjective comments received on insoles made of space fabric, especially PPD made of space fabric 2 with double layers, were generally good that almost all the subjects gave a high rating, while its objective evaluation result was only on the average level. Thus, the misguide caused by the material softness was proven again. Furthermore, samples of insoles manufactured with W \& S were good at loads absorption but gained low scores in the subjective evaluation section. This indicated that although the materials were firm to stand with deformation and with better shock-absorption performance but might not be received as comfort. One more interesting phenomenon found was that the scores of insoles prototype PKS made by single-layer space fabric 1 exceeded PKD, the one with double-layer. While in another case, the scores recorded between PPS (single layer) \& PPD (double layer) which were made by the same space fabric 2 , were almost the same. This might be caused by the super softness of space fabric 1 .

All these findings indicated that, standing in the shoes of insole designer or manufacturers, with the same shock or impact absorption performance, softer materials would provide a more comfortable subjective perception. While standing in the consumers, super-softness tends to trigger a misunderstanding towards their shock absorption performance so that propitiate supportive materials were more appropriate for professional running insole design.

\section{Correlations among 6 different VAS scoring factors}

The correlations between different factors are revealed in Table 6. There is a consistency with the former conclusions drawn that the score for one testing point was closely related to the others. In other words, when a prototype usually performs well in one evaluation aspect, it would also receive positive comments in the other aspects. This result might indicate that subjects tend to rate each item based on their overall comfort degree.

\section{T-Test analysis among different factors}

The result of the T-Test analysis is shown in Table 7. All values are relatively high, indicating that there were no strong connections among the 6 factors within those 8 pairs of different insole samples. It proved that different materials can lead to totally different perception towards the performance of professional running insoles. 
Table 6: Correlations among 6 different VAS scoring factors of subjective evaluation.

\begin{tabular}{|c|c|c|c|c|c|c|}
\hline & Heel Cushioning & Heel Fit & $\begin{array}{c}\text { Forefoot } \\
\text { Cushioning }\end{array}$ & $\begin{array}{c}\text { Medio-lateral } \\
\text { Control }\end{array}$ & Arch Height & Overall Comfort \\
\hline Heel cushioning & 1 & $.880^{* *}$ & $.835^{* *}$ & $.864^{* *}$ & $.848^{* *}$ & $.907^{* *}$ \\
\hline Heel Fit & - & 1 & $.856^{* *}$ & $.880^{* *}$ & $.871^{* *}$ & $.863^{* *}$ \\
\hline Forefoot cushioning & - & - & 1 & $.885^{* *}$ & $.884^{* *}$ & $.899^{* *}$ \\
\hline Medio-lateral control & - & - & - & 1 & $.943^{* *}$ & $.909^{* *}$ \\
\hline Arch Height & - & - & - & - & -1 & $.890^{* *}$ \\
\hline Overall comfort & - & - & - & - & 1 \\
\hline
\end{tabular}

Table 7: T-test of subjective evaluation.

\begin{tabular}{|c|c|c|c|c|c|c|}
\hline & Heel Cushioning & Heel Fit & $\begin{array}{c}\text { Forefoot } \\
\text { Cushioning }\end{array}$ & $\begin{array}{c}\text { Medio-lateral } \\
\text { control }\end{array}$ & Arch Height & Overall Comfort \\
\hline W-PKS & 0.088 & 0.097 & 0.136 & 0.149 & 0.19 & 0.137 \\
\hline W-PKD & 0.172 & 0.628 & 0.668 & 0.708 & 0.87 & 0.436 \\
\hline W-PPS & 0.092 & 0.096 & 0.45 & 0.159 & 0.145 & 0.127 \\
\hline W-PPD & 0.11 & 0.29 & 0.392 & 0.157 & 0.235 & 0.082 \\
\hline W-S & 0.44 & 0.667 & 0.736 & 0.548 & 0.251 & 0.451 \\
\hline W-NS & 0.298 & 0.805 & 0.971 & 0.143 & 0.485 & 0.089 \\
\hline W-ND & 0.171 & 0.312 & 0.692 & 0.167 & 0.209 & 0.084 \\
\hline PKS-PKD & 0.752 & 0.718 & 0.815 & 0.545 & 0.439 & 0.732 \\
\hline PKS-PPS & 1 & 0.971 & 0.641 & 0.672 & 0.947 & 0.319 \\
\hline PKS-PPD & 0.983 & 0.983 & 0.986 & 0.79 & 0.76 & 0.894 \\
\hline PKS-S & 0.574 & 0.62 & 0.358 & 0.373 & 0.657 & 0.508 \\
\hline PKS-NS & 0.713 & 0.248 & 0.289 & 0.925 & 0.359 & 0.931 \\
\hline PKS-ND & 0.738 & 0.628 & 0.447 & 0.876 & 0.805 & 0.967 \\
\hline PKD-PPS & 0.624 & 0.554 & 1 & 0.521 & 0.195 & 0.51 \\
\hline PKD-PPD & 0.422 & 0.169 & 0.4 & 0.254 & 0.21 & 0.228 \\
\hline PKD-S & 0.775 & 0.838 & 0.411 & 0.972 & 0.332 & 0.777 \\
\hline PKD-NS & 0.929 & 0.819 & 0.723 & 0.441 & 0.608 & 0.675 \\
\hline PKD-ND & 0.861 & 0.901 & 0.777 & 0.49 & 0.348 & 0.654 \\
\hline PPS-PPD & 0.965 & 1 & 0.695 & 1 & 0.622 & 0.757 \\
\hline PPS-S & 0.178 & 0.344 & 0.328 & 0.173 & 0.46 & 0.278 \\
\hline PPS-NS & 0.508 & 0.343 & 0.552 & 0.563 & 0.157 & 0.366 \\
\hline PPS-PPD & 0.664 & 0.667 & 0.462 & 0.664 & 0.637 & 0.41 \\
\hline PPD-S & 0.31 & 0.191 & 0.163 & 0.139 & 0.182 & 0.051 \\
\hline PPD-NS & 0.657 & 0.516 & 0.496 & 0.699 & 0.744 & 0.767 \\
\hline PPD-ND & 0.73 & 0.762 & 0.456 & 0.81 & 0.81 & 0.795 \\
\hline S--NS & 0.634 & 0.842 & 0.801 & 0.355 & 0.879 & 0.357 \\
\hline S--ND & 0.594 & 0.79 & 0.51 & 0.301 & 0.667 & 0.341 \\
\hline NS-ND & 0.86 & 0.159 & 0.737 & 0.73 & 0.168 & 0.877 \\
\hline
\end{tabular}

\section{Market situation analysis}

Synthesizing the results both from objective with subjective evaluations, the 8 pairs of professional running insole samples were allocated into different market segments, as shown in Figure 14. Insole Samples W/ S/ NS were placed in the traditional area with good objective measurement result, while Insole Samples PPS/ PKS/ PPD were allocated in a relatively new market place with ideal performance in subjective evaluation. From this deviation, it could be easily told that different material softness entirely differed the evaluation results on subjective and objective testing. 


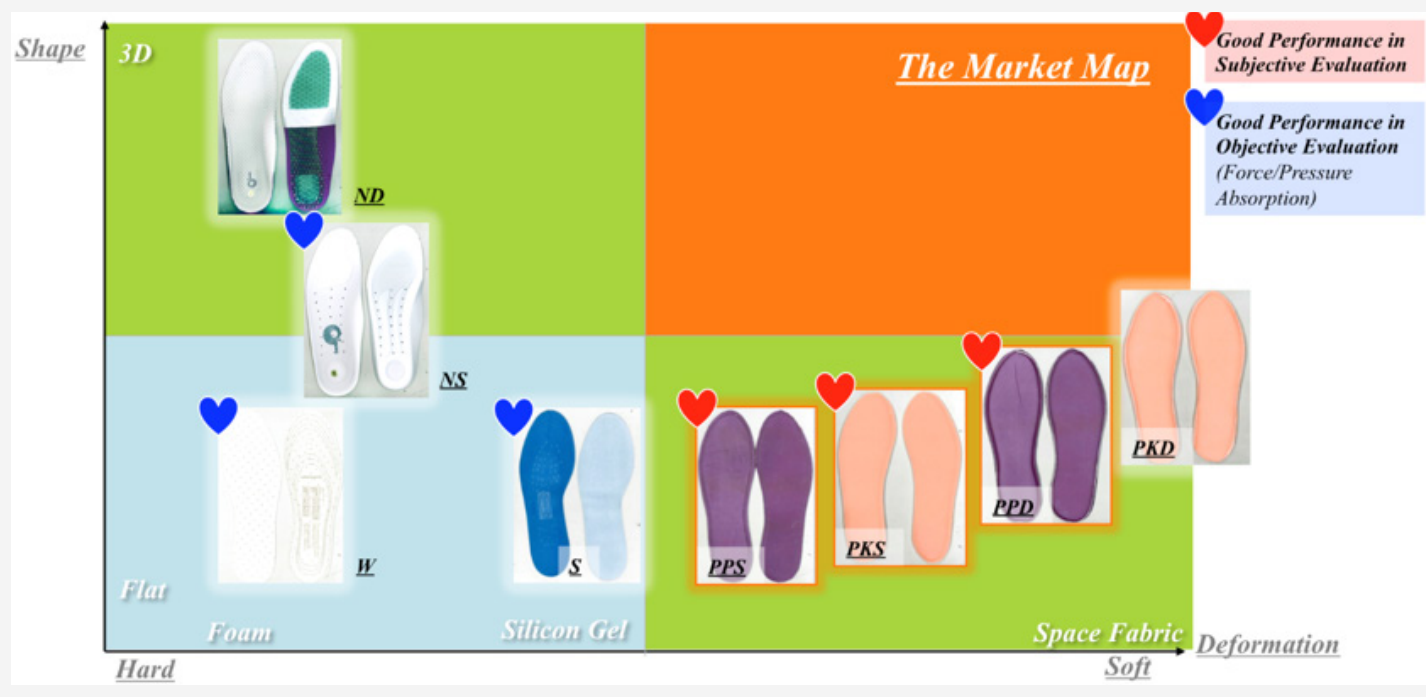

Figure 14: Allocation of the samples of 8 pairs of insoles in market map.

Generally, this research indicates that consumers prefer soft and flat sports insoles thanks to their overall subjective comfortable impression, although these insoles might not performance objectively well in shock absorption and protection. And super material softness might misguide consumers. Therefore, this misguide should be prevented from selecting super soft materials for professional running insole design. Meanwhile, maintaining the shock-absorption function effective at the same level, a softer material is more ideal for insole design to provide a more comfortable wearing experience for consumers.

\section{Conclusion}

In this research, 8 pairs of professional running insoles with different materials softness and design shapes were selected to tested both in subjective comfort evaluation, which was based on the perceptions on 6 VAS scoring factors, and objective shockabsorption protective effectiveness. It was found that material softness would influence consumers' final perceptions that they were easy to be misguided by false subjective comfort feeling. While hard supportive should perform better according to objective testing but with a relative poor subjective perception in contrast. Further, in the subjective testing, the perception on each testing factor was closely related to the others of each sample no matter conducting which gesture. Additionally, these 4 different gestures were conducted by each subject in the wear trial testing to testing the objective shock absorption effectiveness under different scenarios to ensure their overall effectiveness. Last but not the least, maintaining the shock-absorption function effective at the same level, a softer material is more ideal for professional running insole design to provide a more comfortable wearing experience for consumers.

\section{Further Study}

In this research, all the measurements were lab-based instead of real field trial. To evaluate the samples' performance in real fields, further measurement could be done in different scenarios in a long term. Meanwhile, the perspectives about shock waves absorbed are not generally comprehensive that the study focused mainly on 2 gestures, the slow run and fast run. In reality, different gestures will be hold randomly so that more gestures should be considered to analyze the effects more comprehensively.

\section{References}

1. (2018) Sporting goods store sales in the United States from 1992 to 2016 (in billion U.S. dollars).

2. Barton CJ, Lack S, Malliaras P, Morrissey D (2012) Gluteal muscle activity and patellafemoral pain syndrome: a systematic review. Br J Sports Med 47: 207-214.

3. Hreljac A (2004) Impact and overuse injuries in runners. Med Sci Sports Exerc 36(5): 845-849.

4. James SL, Bates BT, Osternig LR (1978) Injuries to runners. Am J Sports Med 6(2): 40-50.

5. Milner CE, Ferber R, Pollard CD, Hamill J, Davis IS (2006) Biomechanical factors associated with tibial stress fracture in female runners. Med Sci Sports Exerc 38(2): 323-328.

6. Ogon M, Aleksiev AR, Spratt KF, Pope MH, Saltzman CL (2001) Footwear affects the behavior of low back muscles when jogging. Int J Sports Med 22: 414-419.

7. Che H, Nigg BM, de Koning J (1994) Relationship between plantar pressure distribution under the foot and insole comfort. Clin Biomech (Bristol, Avon) 9(6): 335-341.

8. Mündermann A, Nigg BM, Stefanyshyn DJ, Humble RN (2002) Development of a reliable method to assess footwear comfort during running. Gait Posture 16(1): 38-45.

9. O'Leary K, Vorpahl KA, Heiderscheit B (2008) Effect of cushioned insoles on impact forces during running. J Am Podiatr Med Assoc 98(1): 36-41.

10. Leber C, Evanski PM (1986) A comparison of shoe insole materials in plantar pressure relief. Prosthet Orthot Int 10(3): 135-138.

11. Whittle MW, Orofino TA, Miller K (1993) Relationship between mechanical properties of carpet and comfort in walking. J Biomech 26(3): 323. 